\title{
G070 DINUCLEAR NICKEL(II)COMPLEXES AS MODELS FOR THE ACTIVE SITE OF UREASE
}

\section{Volkmer and B. Krebs}

Westfalische Wilhelms-Universitat Munster, Anorganisch-Chemisches Institut, Wilhelm-Klemm-Str. 8, D-4400 Manster, Germany

Urease (urea amidohydrolase, EC 3.5.1.5) catalyzes the hydrolysis of urea. The reaction products at physiological $\mathrm{pH}$ are ammonium- and hydrogen carbonate ions. Ureolytic activity is widespread in the environment and therefore urea is a common source of nitrogen fertilization in agricultural production. Although urease was the first enzyme to be isolated (by J.B. Sumner in 1926) the actual reaction path of the enzymatic hydrolysis is still unknown. The active center of the plant urease from jack beans contains two nickel(II)ions per subunit and nickel(II)ions are also found in microbial ureases '. We are trying to model the enzymatic active site by $\mathrm{X}$-ray crystal structure investigations of a number of dinuclear nickel(II)-compounds. Ligation of the nickel(II)ions is achieved by the N,N-bis(2benzimidazolylmethyl)amino function. Two of these simple tripod ligands are assembled by spacing groups of the type shown in figure 1 . The coordination geometries and the distances between the nickel(II)ions are controlled by the spacer. As an example we report here the synthesis, structural and spectroscopic properties of $\left[\mathrm{Ni}_{2}(\mathrm{~L})(\mathrm{ac})\left(\mathrm{H}_{2} \mathrm{O}\right)\right]\left(\mathrm{ClO}_{4}\right)_{2} \cdot \mathrm{C}_{4} \mathrm{H}_{10} \mathrm{O} \cdot 0.5 \mathrm{H}_{2} \mathrm{O}$ where $\mathrm{HL}$ is $\mathrm{N}, \mathrm{N}, \mathrm{N}^{\prime}, \mathrm{N}^{\prime}$ tetrakis (2-benzimidazolylmethyl)-2-hydroxy-1,3-diaminopropane. The cation of the complex contains a $\mu$-alkoxo- $\mu$-acetato-bridged unit in which two nickel(II)ions are situated in close proximity (compare figure 2). Interestingly, the coordination sphere of the metal ions is different: one of the metal ions is five-coordinated with a free coordination site while the other one finds

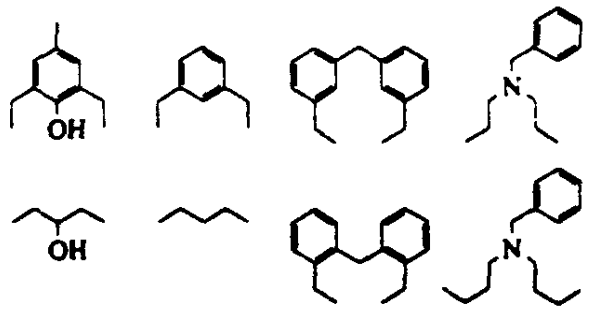

FIGURE 1: Spacers used to connect the N,N-bia(2-benzimidazolymathy)amino group

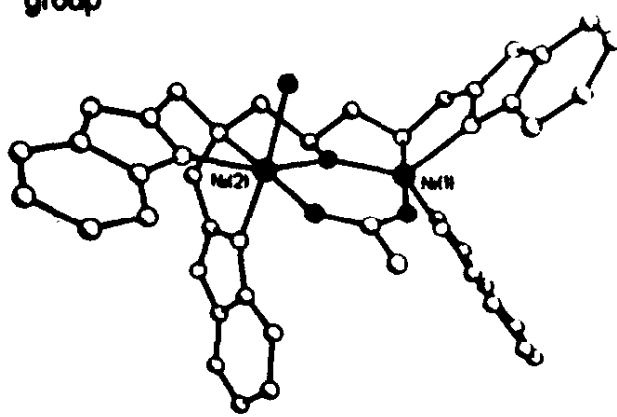

FIGURE 2: The $\left[\mathrm{Ni}_{2}(\mathrm{~L})(\mathrm{ac})\left(\mathrm{H}_{2} \mathrm{O}\right)\right]^{2+}$ cation itself in a distorted octahedral environment with an additional water molecule within its coordination sphere. In aprotic weakly coordinating solvents such as nitroethane it is possible to add a single substrate molecule to the cation. Our present interest deals with the question whether the coordinated water molecule can act as a Lewis acid-activated nucleophile that attacks the substrate molecule attached to the opposite nickel(II)ion. Kinetic measurements are underway, e.g. the reaction spectra of the complex-catalyzed hydrolysis of appropriate substrates such as p-nitrophenylurea in different solvents are recorded. On the base of our results it will be possible to verify the proposed reaction mechanism for the action of the active center of the urease ${ }^{2}$. Like other dinuclear metal complexes the urease model compounds are promising candidates for novel catalysts in organic synthesis and for use in analytical applications (chemosensors) as well.

$1 \quad$ H.L.T. Mobley and R.P. Hausinger, Microbiol. Rev., 53, 85 (1989);

2 N.E. Dixon, P.W. Riddles, C. Gazzola, R.L. Blakeley and B. Zerner, 